\title{
A Design Thinking Approach to the Design of a Digital Tool to Support People on a Weight Management Journey
}

\author{
Paul Doney \\ Leeds Beckett University \\ Leeds, UK \\ p.doney@leedsbeckett.ac.uk
}

\begin{abstract}
The application of digital tools in support of people making a positive behaviour change is well established. However, it has been observed that the impact is not as significant as predicted. The aim of this project was to investigate whether a Design Thinking approach could generate new insights that could be used to drive the development of an innovative application to help people on their weight management journey. Findings show that although no radically new user needs were identified, careful planning emerged as the most significant challenge; which contrasts with the heavy focus of commercially available apps on calorie and activity tracking.
\end{abstract}

User Centred Design, Design Thinking, Behaviour Change, Weight Management, mHealth

\section{INTRODUCTION}

The growth in the application of digital tools to address health issues has become increasingly attractive, and numerous systematic studies have been published (Preeth, et al., 2014) (Pellegrini, et al., 2015) (Payne, et al., 2015) in an attempt to understand the impact of these tools. Whilst there is evidence of a positive impact in these studies, the prevalence of negative results suggests that there is no guaranteed level of success and it is accepted that the magnitude of any impact is at best modest (Covolo, et al., 2017) or indeed variable and not sustainable (Kohl, et al., 2013).

In the weight management domain, face-to-face weight loss interventions have been adjudged to be successful, producing weight reductions of approximately $10 \%$ for participants (Kozak, et al., 2017). But the expense and inflexibility of these programs limits their reach, consequently the search for improved digital tools in this domain continues (Kozak, et al., 2017).

The project reported on in this paper set out to seek new insights into how technology could be applied to the weight management context. The longer term aim being to develop innovative applications that respond to the new knowledge gained. To gain new insights, a Design Thinking approach was adopted.

\section{RELATED WORK}

Design Thinking or Service Design Thinking is a human-centered design methodology that uses codesign and intuitive problem-solving techniques to match people's needs with what is technologically feasible and organizationally viable (Brown T, et al., 2010). End-users are involved at every stage. It is typically applied to deal with difficult, multidimensional problems that lack recognizable requirements and solutions - so-called "wicked problems" (Rittel \& Weber, 1973).

The framework that was adopted for this project was the one developed by the Hassno Plattner Design Institute (D.School, 2017). Other notable alternatives are offered by IDEO (IDEO, 2017) and the UK Design Council (Design Council, n.d.). The D.School framework identifies five overlapping and inter-related activities (D.School, 2017):

$\begin{aligned} \text { (i) } & \text { Empathize } \\ \text { (ii) } & \text { Define } \\ \text { (iii) } & \text { Ideate } \\ \text { (iv) } & \text { Prototype } \\ \text { (v) } & \text { Test }\end{aligned}$

The user engagement activities related to the Define and initial Ideate stages of the project were reported on previously (Doney \& Fabri, 2015). The 
analysis of the data emerging from that engagement identified 4 key challenges:

(i) In it for the Long Run - recognising that managing weight for someone that has become obese will be a lifetime concern.

(ii) Securing Support - getting appropriate support from those that are closest to you and most influential.

(iii) Avoiding Temptation - dealing with temptation that if not resisted will impact negatively on plans.

(iv) Low Mood- dealing with life's ups and downs without a negative impact on weight loss plans.

The next stage was to explore these challenges further and start to develop ideas of how a digital tool might help clients address them.

\section{USER ENGAGEMENT}

During the project the design of workshops was influenced by various parties including people engaged on structured weight loss programs run by UK based organizations specializing in face-to-face support (MoreLife UK Ltd, ABL Health Ltd., Health for all), weight loss program organizers and facilitators employed by collaborating organizations, Design Thinking practitioners (Uscreates Ltd.) and academics from Leeds Beckett University.

\subsection{Trial Workshop}

The first activity undertaken during this phase was to develop personas (Neilsen, 2011) to represent each of the challenges. It was decided to do this with participants of a weight loss program to maximize the veracity of the personas. Then to use these personas to trigger a discussion, as to how a digital tool could be deployed to assist someone faced with these challenges.

This wasn't as successful as had been hoped. Participants found it difficult to build personas from anything other than their own experience and as a result were reluctant to share personal details, when there had been little time for trust to build. With weak personas it proved difficult to trigger discussion into potential digital tools. Whist the workshop proved useful in building further empathy with target users for the service to be developed, more was learnt about how to run an effective workshop, than was learnt about the challenge briefs. As part of the analysis of the initial workshops, an assessment was made of workshop format and key success characteristics were identified (Doney \& Fabri, 2015). These were: (i) The atmosphere at the start of workshops can be lightened by the use of staging to communicate a sense of occasion.

(ii) The focus of participants can be clearly intensified by the presentation of their role as one that was integral to the project and of greater importance than the facilitators.

(iii) The use of playful and physical activity can keep the energy in a room and commitment to a workshop, at a high level.

(iv) The gathering of data in a visual form allows for a 'quick and dirty' analysis that fully involves participants as well as facilitators.

(v) The generation of output that could be easily shared and viewed collectively can be a very effective way to maintain momentum and engagement.

In re-examining the workshop it was recognised that the workshop design was too static and that the data gathering was not as effective as it could have been. Critically, it was realised that a stronger sense of anonymity was needed - something that could be achieved by providing outline personas, rather than asking participants to develop them. Similarly, after reflecting on the difficulty of generating ideas for digital tools, it was realised that participants needed clearer ideas to work with and it was over ambitious to think that new and innovative design solutions would emerge - the focus of future workshops needed to address the participant's area of expertise: weight loss.

\subsection{Main Workshop}

Personas were developed to represent the four challenges (both male and female version), these were posted on the wall at the beginning of the workshop, so that participants could peruse them as they waited for the workshop to begin. A facilitator was allocated to each persona. Participants were then given an opportunity to gravitate towards a particular persona, so that each facilitator was working with at least two people. A short period was given over to each group exploring their persona and adding further details. After this period of familiarisation, each group explored their challenge brief, considering what fuelled the challenge under the title of 'What are the causes' and considered what reduced the challenge under the title of 'What are the helpers'. All input was gathered on post-it notes.

People were then asked to look at all the causes and helpers and identify which three they felt were most significant, applying a sticker to each of their choices, such that a picture of the most popular developed. Groups then undertook a 'How Might We' (D.School, 2017) exercise on the most popular choices to generate ideas of how to mitigate causes and/or support helpers. With ideas again 
being noted down by the facilitator, before being transferred to post-it notes.

\section{ANALYSIS}

The Design Thinking methodology provided the framework for extracting a rich set of qualitative data, but little direction in terms of structured analysis. The abductive nature of Design Thinking (Dorst, 2011) leads to the gathering of data without any pre-emptive coding, in that respect the methodology has a similar nature to recognized research methodologies, such as Grounded Theory Method (Strauss \& Corbin, 2014) or Design Ethnography (Baskerville \& Myers, 2015). The former suggests a coding approach that starts with an open coding (codifying all data collected and identifying categories), axial coding (seeking connections between categories) and selective coding (identifying the core category and the relationship of other categories to it). This approach to coding was used to guide the analysis of all the data collected during the workshops.

The open coding process was previously applied to identify the four challenges, so the initial task here was to align the data gathered with the challenges and seek axial codes. Some sub themes began to emerge within each challenge, which included some that revealed links, for example group support was a strong theme within 'In it for the Long Run'. However, it was difficult to identify strong links when analysing one challenge at a time, so the data was analysed as a single set.

A 'Saturate and Group' (D.School, 2017) approach was taken, looking for connections then building groups around those, iterating until strong groupings emerged. Initially this resulted in 4 groupings that cut across the initial 4 challenges. These were Support, Concerns, Long-Term Plans and Short-Term Plans.

In re-examining the data to derive selective codes that captured the core messages, it was quickly seen that the majority of Concerns related to Support, with the remainder connected to planning. As Short Term Planning and Long Term Planning can easily be coded simply as Planning, only two codes remained: Planning and Support. Of these Planning was the dominant code.

Drawing influence from the $\mathrm{HCl}$ practice of applying time efficient methods (Baillie \& Morton, 2010), a 'Quick and Dirty' review of mobile apps currently available on the Google Play store was completed.

The following search terms were applied:

(i) 'weight loss diet life coach tracker'

(ii) 'weight loss diet slim slimming'

(iii) 'weight loss exercise fitness workout'

(iv) 'weight loss coach'
The first 50 returns for each search term was noted and each app returned was explored. In the initial analysis all apps that didn't focus on weight loss and were not in English were removed. All repeated instances were identified. This left 30 apps to be explored in depth to ascertain common features. 28 of the 30 offered weight and or $\mathrm{food} /$ calorie tracking and reporting. 15 out of the 30 offered planning guidance in the form of tips, recipes and diet plans, but none of the apps returned by the search offered an interactive planning experience beyond initial goal setting.

\section{DISCUSSION}

It has been recognized that multi component interventions (Payne, et al., 2015) and ones that are underpinned by recognized behaviour change strategies (Webb, et al., 2010), have the most significant impact on the success of a digital tool, when applied to support positive lifestyle changes. However, it is unclear which elements it is best to combine and how to present them.

A number of systematic reviews that have been undertaken have sought to identify common practice as well as best practice. Self-monitoring is the feature that has been identified in a number of reviews as the dominant feature in mobile app based weight management interventions (Pellegrini, et al., 2015; Zhao, et al., 2016; Payne, et al., 2015). A recent study found that $75 \%$ of top rated smartphone apps for weight loss were narrowly reliant on a food database and calorie tracking (Rivera, et al., 2018). Further to that observation Rivera et al. (2018) found that their client group identified assistance with food planning as the key function in an app, with only $11 \%$ of apps providing this assistance. Similarly, this lack of focus on meal planning as a potentially powerful behaviour change tool, has been overlooked in scientific study (Ducrot, et al., 2017) .

Keller and Siegrist (2015) provide further evidence that calorie and activity tracking does not warrant its dominant place in the design of apps. In developing their weight management strategies inventory (WMSI) to measure dieting success, they identified 19 successful strategies applied by people on a weight loss journey. The most successful of these were related to food substitution and portion size, with weight monitoring the 15th out of 19 success strategies and calorie counting the 12th most successful.

This project suggests -whilst not dismissing tracking as a key component to the successful application of a digital tool - that the development of a tool that is focused on planning, backed up by a support network, would address more directly the main challenges faced by those starting a weight management journey. 


\section{REFERENCES}

Baillie, L. \& Morton, L., 2010. Designing Quick \& Dirty Applications for Mobiles: Making the Case for the Utility of $\mathrm{HCl}$ Principles. Journal of computing and information technology, 18(2).

Baskerville, R. \& Myers, M., 2015. Design Ethnography in Information Systems. Information Systems Journal,, 25(1), pp. 23-46.

Brown T, W. J., Brown, T. \& Wyatt, J., 2010. Design Thinking for Social Innovation.. Stanford Social Innovation Review, 8(1), pp. 29-35.

Covolo, L. et al., 2017. Does evidence support the use of mobile phone apps as a driver for promoting healthy lifestyles from a public health perspective? A systematic review of Randomized Control Trials.. Patient Education and Counselling, 100(12), pp. 2231-2243.

D.School, S., 2017. Design Thinking Bootleg. [Online]

Available

at:

https://dschool.stanford.edu/resources/thebootcamp-bootleg

Design Council, n.d. [Online] Available at: https://www.designcouncil.org.uk/ [Accessed 13th May 2018].

Doney, P. \& Fabri, M., 2015. Seeking New Insights: A Design Thinking Approach to Persuasive Technology Aimed at Supporting Clients of a Weight Management Program. Bucharest, $\mathrm{RoCHI}$ Conference Proceedings.

Dorst, K., 2011. The core of 'design thinking' and its application. Design Studies, pp. 521-532.

Ducrot, P. et al., 2017. Meal planning is associated with food variety, diet quality and body weight status in a large sample of French adults. International Journal of Behavioral Nutrition and Physical Activity, Volume 14.

IDEO, 2017. Design Thinking Resources. [Online] Available at: https://www.ideou.com/pages/design-thinkingresources

Keller, C. \& Siegrist, M., 2015. The weight management strategies inventory (WMSI). Development of a new measurement instrument, construct validation, and association with dieting success. Appetite, Volume 92, pp. 322-36.

Kohl, L. F., Crutzen, R. \& deVries, N. K., 2013. Online Prevention Aimed at Lifestyle Behaviors: A Systematic Review of Reviews. Journal of Medical Interent Reserach, p. 15(7).

Kozak, A., Buscemi, J., Hawkins, M. \& Wang, M., 2017. Technology-based interventions for weight management: current randomized controlled trial evidence and future directions. Journal of Behavioural Medicine, 40(1), pp. 99-111.

Neilsen, L., 2011. Personas in Co-creation and Codesign. Copenhagen, Copenhagen Business School Press, pp. 38-40.

Payne, H., Lister, C., West, J. H. \& Bernhartdt, J. M., 2015. Behavioral Functionality of Mobile Apps in Health Interventions: A Systematic Review of the Literature. [Online] Available at: https://www.ncbi.nlm.nih.gov/pmc/articles/PMC4 376122/

[Accessed 14 May 2018].

Pellegrini, C., Pfammatter, A. F., Conroy, D. E. \& Spring, B., 2015. Smartphone applications to support weight loss: current perspectives. [Online]

Available

at:

https://www.ncbi.nlm.nih.gov/pmc/articles/PMC4 $520704 /$

[Accessed 13th May 2018].

Preeth, S. et al., 2014. An Evaluation of Mobile Health Application Tools. [Online] Available at: https://www.ncbi.nlm.nih.gov/pmc/articles/PMC4 $114419 /$

[Accessed 13th May 2018].

Rittel, H. W. \& Weber, M. M., 1973. Dilemmas in a general theory of planning.. Policy sciences, pp. 155-169.

Rivera, J. et al., 2018. User-Centered Design of a Mobile App for Weight and Health Management in Adolescents With Complex Health Needs: Qualitative Study. JMIR Formativ Res, 2(1).

Strauss, A. \& Corbin, J., 2014. Basics of Qualitative Research. Thousand Oaks: Sage.

Tang, J., Abraham, C., Stamp, E. \& Greaves, C., 2015. How can weight-loss app designers' best engage and support users? A qualitative investigation. British Journal of Health Psychology, Volume 20, pp. 151-171.

Webb, T. L., Joseph, J., Yardley, L. \& Michie, S., 2010. Using the Internet to Promote Health Behavior Change: A Systematic Review and Meta-analysis of the Impact of Theoretical Basis, Use of Behavior Change Techniques, and Mode of Delivery on Efficacy. Journal of Medical internet Research, 12(1).

Zhao, J., Freeman, B. \& Li, M., 2016. Can Mobile Phone Apps Influence People's Health Behaviour Change? An Evidence Review. [Online]

Available at: https://www.ncbi.nlm.nih.gov/pubmed/27806926 [Accessed 13th May 2018]. 